\title{
IMPLEMENTASI PENGUKURAN PRODUKTIVITAS DENGAN METODE MARVIN E. MUNDEL DI UKM ROTI BERNAS
}

\author{
Oscar Nemesis ${ }^{1}$ \\ ${ }^{1}$ Program Studi Teknik Industri, Universitas Katolik Musi Charitas \\ Jln. Bangau No. 60, Palembang, Sumatera Selatan \\ *Penulis Korespondensi: oscarnemesis66@gmail.com
}

\begin{abstract}
Bread Bernas SME is a home industry that is engaged in producing bread. The problems that exist in Bread Bernas SME are the amount of bread production that cannot meet production targets and production costs such as raw material costs have increased but the amount of production output has decreased. This study aims to determine the productivity index, influencing factors, and proposed improvements to increase productivity. This productivity measurement uses the Marvin E. Mundel method by calculating the partial and total productivity indices. The results of the productivity index for each input (depreciation, labor, materials, electrical energy, and maintenance) in 2020 as a period measured successively are $80.76 \%$; $84.40 \%$; $87.76 \%$; $102.10 \%$; $68.30 \%$; and a total index of $87.02 \%$. To increase productivity, it can be implemented such as adding radios and speakers, adding fans, implementing a floor cleaning schedule and production machines, and so on. Implementation is carried out in April and May 2021. The results of the productivity index after implementation of each input (depreciation, labor, materials, electrical energy, and maintenance) in April 2021 respectively are 103.17\%; 106.48\%; 113.45\%; 112.04\%; $107.89 \%$ and a total index of $112.06 \%$. Meanwhile, the productivity index in May 2021 was $106.07 \%$ in a row; 107.36\%; 111.74\%; 110.20\%; 102.43\%; and the total index is $109.55 \%$.
\end{abstract}

Keywords: SME, Measurement, Productivity, Marvin E. Mundel, Cause and Effect Diagram

\section{Pendahuluan}

Produktivitas merupakan suatu aspek yang penting bagi perusahaan karena produktivitas dapat dijadikan pedoman untuk mengetahui kinerja yang dicapai baik kinerja individu, kelompok, industri, maupun kinerja perekonomian secara keseluruhan (Sinungan, 2015). Suatu perusahaan perlu mengetahui pada tingkat produktivitas mana perusahaan tersebut beroperasi agar dapat membandingkan dengan produktivitas yang telah ditetapkan oleh manajemen (Masharyono, 2016). Pada saat ini perusahaan dituntut untuk lebih meningkatkan produktivitasnya. Hal ini dilakukan karena dalam menghadapi situasi bisnis yang semakin kompetitif dan perubahan lingkungan yang semakin cepat. Setiap perusahaan diharapkan dapat mengolah semua sumber daya yang dimiliki secara efektif dan efisien agar mampu menghasilkan produk yang berkualitas tinggi. Salah satu cara untuk mengetahui bahwa efisiensi penggunaan sumber-sumber daya sebagai input telah berhasil diminimalisirkan atau dihematkan adalah dengan cara mengetahui nilai produktivitas. UKM Roti Bernas merupakan industri rumah tangga yang bergerak di bidang produksi makanan khususnya roti. UKM Roti Bernas dalam melakukan penilaian kinerja perusahaannya hanya berdasarkan output produksinya dan juga hanya menghitung profit dari hasil penjualan produksi sebagai ukuran baik atau tidaknya produktivitas di UKM.

Akar permasalahan produktivitas yang ada di UKM Roti Bernas yaitu 
berdasarkan laporan biaya produksi bulanan, terjadi penurunan output produksi dari UKM Roti Bernas. Penggunaan diagram sebab akibat dapat menunjukkan faktor-faktor penyebab penurunan produktivitas. Input yang digunakan dalam metode Marvin E. Mundel ini yaitu depresiasi, material, tenaga kerja, energi serta maintenance. Dengan mengetahui faktor-faktor tersebut, maka dapat ditekan penurunan produktivitas dengan membuat usulan perbaikan untuk diimplementasikan agar kegiatan produksinya dapat meningkat serta tujuan produktivitas dari UKM dapat tercapai.

\section{Tinjauan Pustaka \\ Produktivitas}

Produktivitas adalah perbandingan antara output (barang dan jasa) dibagi dengan input (sumber daya, seperti tenaga kerja dan modal) (Heizer dan Barry, 2016). Produktivitas sebagai perbandingan antara totalitas pengeluaran pada waktu tertentu dibagi totalitas masukan selama periode tersebut (Sinungan, 2015). Produktivitas juga diartikan sebagai perbandingan ukuran harga bagi masukan dan hasil, perbedaan antara kumpulan jumlah pengeluaran dan masukan yang dinyatakan dalam satu satuan (unit) umum. Rumus produktivitas dapat digambarkan dalam rumus berikut.

Produktivitas $(\mathrm{P})=\frac{\text { output }}{\text { Input }}$

Menurut Sinaga (2015), mengemukakan bahwa dalam melakukan pengukuran produktivitas diperlukan kriteria agar dapat membantu dalam mendapatkan ukuran produktivitas yang berarti. Model pengukuran produktivitas yang paling sederhana adalah pendekatan dengan menggunakan rasio output dibagi dengan input (Gaspersz, 2005). Pengukuran produktivitas berdasarkan pendekatan rasio output dibagi dengan input ini akan dapat menghasilkan tiga jenis ukuran produktivitas, antara lain :

a. Produktivitas Faktor Total ( total factor productivity). b. Produktivitas Total (total factor productivity).

c. Produktivitas Parsial (partial productivity).

\section{Unsur Produktivitas}

Menurut Sumanth

menyatakan bahwa ada 3 unsur pokok produktivitas yang harus dipahami, yaitu:

1. Efisiensi

Efisiensi merupakan suatu ukuran dalam membandingkan penggunaan masukan yang direncanakan dengan penggunaan masukan yang sebenarnya terlaksana. Pengertian efisiensi berorientasi ada masukan atau ukuran penghematan pemakaian sumber-sumber produksi ataupun kegiatan organisasi, seperti penghematan dalam pemakaian bahan, listrik, uang, tenaga kerja, waktu, ruangan, air, dan sebagainya.

2. Efektivitas

Efektivitas menunjukkan sejauh mana target dapat tercapai, baik secara kuantitas maupun waktu. Makin besar presentase target tercapai makin tinggi pula tingkat efektivitasnya. Konsep ini berorientasi pada keluaran. Peningkatan efektivitas belum tentu dibarengi dengan peningkatan efisiensi dan demikian pula sebaliknya.

3. Kualitas

Produktivitas merupakan ukuran kualitas. Kualitas masukan dan kualitas proses akan meningkatkan kualitas keluaran. Keluaran yang berkualitas baik akan meningkatkan rasio output per input dalam nilai atau nilai tambah, berarti meningkatkan daya saing atau produktivitas.

\section{Siklus Produktivitas}

Sumanth (1990) memperkenalkan suatu konsep formal yang disebut dengan siklus produktivitas (productivity cycle) yang dipergunakan dalam peningkatan produktivitas secara terus menerus.

Pada dasarnya konsep siklus produktivitas terdiri dari 4 tahap utama, yaitu:

1. Pengukuran Produktivitas 
(Productivity Measurement).

2. Evaluasi Produktivitas (Productivity Evaluation).

3. Perencanaan Produktivitas (Productivity Planning).

4. Peningkatan Produktivitas (Productivity Improvement).

\section{Metode Marvin E. Mundel}

Model Marvin E. Mundel ini pada dasarnya adalah membandingkan antara produktivitas pada waktu pengukuran dengan produktivitas pada waktu dasarnya. Terdapat dua bentuk pengukuran indeks produktivitasnya, yaitu :

a. $\mathrm{IP}=\frac{\text { AOMP } / \mathrm{RIMP}}{\mathrm{AOBP} / \mathrm{RIBP}} \times 100$

b. IP $=\frac{\text { AOMP } / \text { AOBP }}{\text { RIMP } / \text { RIBP }} \times 100$

Dimana:

IP $=$ Indeks produktivitas.

AOMP = Output agregat untuk periode yang diukur.

AOBP $=$ Output agregat untuk periode dasar.

RIMP = Input untuk periode yang diukur.

RIBP = Input untuk periode dasar.

Menurut Anggraini (2013), langkahlangkah dalam pengukuran produktivitas dengan menggunakan metode Marvin E. Mundel.

a. Perhitungan Total Resources Input Partial (RIP)

RIP = Biaya depresiasi + biaya material + biaya tenaga kerja + biaya energi + biaya maintenence

b. Perhitungan Agregat Output Agregat Output $=($ Jumlah produksi x harga jual produksi)

c. Perhitungan Indeks Produktivitas Parsial

Perhitungan indeks produktivitas parsial dilakukan dengan membandingkan nilai indeks salah satu input (biaya material, tenaga kerja, depresiasi, energi, maintenence).

d. Perhitungan Indeks Produktivitas Total

Perhitungan indeks produktivitas total adalah perbandingan nilai total indeks produktivitas output dengan total nilai indeks produktivitas input suatu periode dengan indeks produktivitas periode sebelumnya.

Suatu input mengalami peningkatan atau penurunan produktivitas dapat dilihat dari nilai indeks produktivitas (IP) yang didapat. Kriteria nilai IP (Indeks Produktivitas) dapat dilihat sebagai berikut :

a. Nilai IP yang didapat $<100$, artinya produktivitas menurun, dan produktivitas pada waktu pengukuran lebih kecil daripada produktivitas pada waktu dasar.

b. Nilai IP yang didapat $=100$, artinya produktivitas tetap, dan produktivitas pada waktu pengukuran sama dengan produktivitas pada waktu dasar.

c. Nilai IP yang didapat > 100, artinya produktivitas meningkat, dan produktivitas pada waktu pengukuran lebih besar daripada produktivitas pada waktu dasar.

\section{Metodologi Penelitian \\ Objek Penelitian}

Penelitian dilakukan dengan melakukan pengamatan secara langsung di UKM Roti Bernas dengan tujuan untuk mengetahui keadaan dan masalah yang ada pada UKM tersebut. Setelah melakukan pengamatan dilanjutkan dengan wawancara untuk mengetahui hal-hal apa yang membuat produktivitas menjadi kurang baik. Setelah melakukan pengamatan dilanjutkan dengan wawancara dengan pemilik usaha untuk mengetahui hal-hal apa yang membuat produktivitas menjadi kurang baik.

\section{Pengumpulan Data}

Pengumpulan data bertujuan untuk untuk mengetahui lebih rinci data-data yang berkenaan dengan penelitian. Pengumpulan dilakukan dengan cara mencatat data yang tersedia di perusahaan dan melakukan wawancara dengan pihak UKM. Adapun data-data yang diperlukan dalam penelitian ini yaitu Data Umum Perusahaan, Data Biaya Depresiasi, Data Biaya Material, Data Biaya Tenaga Kerja, Data Biaya 
Energi, Data Biaya Maintenance, dan Data Jumlah Produksi (Output).

\section{Pengolahan Data}

Pengolahan data yang dilakukan untuk pengukuran produktivitas dengan metode Marvin E. Mundel. Perhitungan data input dan output menggunakan 2 periode waktu tahunan yaitu tahun 2019 digunakan sebagai periode dasar dan tahun 2020 digunakan sebagai periode yang diukur.

Setelah mengetahui hasil indeks produktivitas yang menurun, digunakanlah diagram sebab akibat untuk mengetahui faktor-faktor yang menyebabkan penurunan produktivitas. Kemudian membuat tabel $5 \mathrm{~W}+1 \mathrm{H}$ untuk usulan perbaikan dan diterapkan pada UKM Roti Bernas. Setelah dilakukan penerapan usulan perbaikan, dilakukan pengecekan dan menganalisis tingkat produktivitas yang didapat.

\section{Hasil dan Pembahasan \\ Data Input dan Output}

Data input dan output menggunakan 2 periode tahun yaitu tahun 2019 (periode dasar) dan tahun 2020 (periode yang diukur) dapat ditunjukkan pada tabel 1 berikut ini.

Tabel 1. Data Input dan Output

\begin{tabular}{|c|c|c|c|}
\hline No & Keterangan & $\begin{array}{c}\text { Tahun } 2019 \\
\text { (Periode dasar) }\end{array}$ & $\begin{array}{c}\text { Tahun } 2020 \\
\text { (Periode yang diukur) }\end{array}$ \\
\hline \multicolumn{4}{|c|}{ Output } \\
\hline 1 & Roti Tawar & $\operatorname{Rp} 352.212 .000$ & Rp 306.060.000 \\
\hline 2 & Roti Tawar Kupas & Rp 286.110.000 & Rp 252.830.000 \\
\hline 3 & Roti Manis & $\mathrm{Rp} 458.700 .000$ & Rp 330.280.000 \\
\hline & Total Output & Rp 1.097.022.000 & Rp 889.170.000 \\
\hline \multicolumn{4}{|c|}{ Input } \\
\hline 1 & Depresiasi & $\operatorname{Rp} 5.215 .200$ & Rp 5.216.640 \\
\hline 2 & Biaya Tenaga Kerja & Rp 105.000 .000 & $\operatorname{Rp} 100.450 .000$ \\
\hline 3 & Material & Rp 454.922.000 & Rp 418.705.000 \\
\hline 4 & Energi Listrik & Rp 2.286.000 & Rp 1.808 .000 \\
\hline \multirow[t]{2}{*}{5} & Maintenance & $\mathrm{Rp} 2.272 .000$ & Rp 2.445.000 \\
\hline & Total Input & Rp 569.695.200 & Rp 528.624.640 \\
\hline
\end{tabular}

\section{Hasil Indeks Produktivitas Parsial dan Total}

Berikut ini pada tabel 2 yang menunjukkan hasil indeks produktivitas parsial dan total pada UKM Roti Bernas terhadap masing-masing jenis input setelah penghitungan produktivitas sesuai dengan rumus dari metode Marvin E. Mundel.

Tabel 2. Hasil Indeks Produktivitas UKM Roti Bernas

\begin{tabular}{llccc}
\hline No & Jenis Input & $\begin{array}{c}\text { Tahun 2019 } \\
\text { (Periode } \\
\text { Dasar) }\end{array}$ & $\begin{array}{c}\text { Tahun 2020 } \\
\text { (Periode yang } \\
\text { diukur) }\end{array}$ & Perubahan (\%) \\
\hline 1 & Depresiasi & 100 & 81,03 & $-18,97 \%$ \\
2 & Tenaga Kerja & 100 & 84,72 & $-15,28 \%$ \\
3 & Material & 100 & 88,06 & $-11,94 \%$ \\
4 & Energi Listrik & 100 & 102,48 & $+2,48 \%$ \\
5 & Maintenance & 100 & 75,32 & $-24,68 \%$ \\
6 & Indeks Total & 100 & 87,35 & $-12,65 \%$ \\
\hline
\end{tabular}

\section{Diagram Sebab Akibat}

Pembuatan diagram sebab akibat ini bertujuan agar dapat memperlihatkan faktor-faktor penyebab (root cause) dan 
karakteristik kualitas yang (effect) disebabkan oleh faktor-faktor penyebab itu (Ariani, 2004). Diagram sebab akibat digunakan untuk mencari faktor-faktor yang menyebabkan penurunan produktivitas pada UKM Roti Bernas. Adapun gambar diagram sebab akibat dapat dilihat pada gambar 1, gambar 2, gambar 3, dan gambar 4.

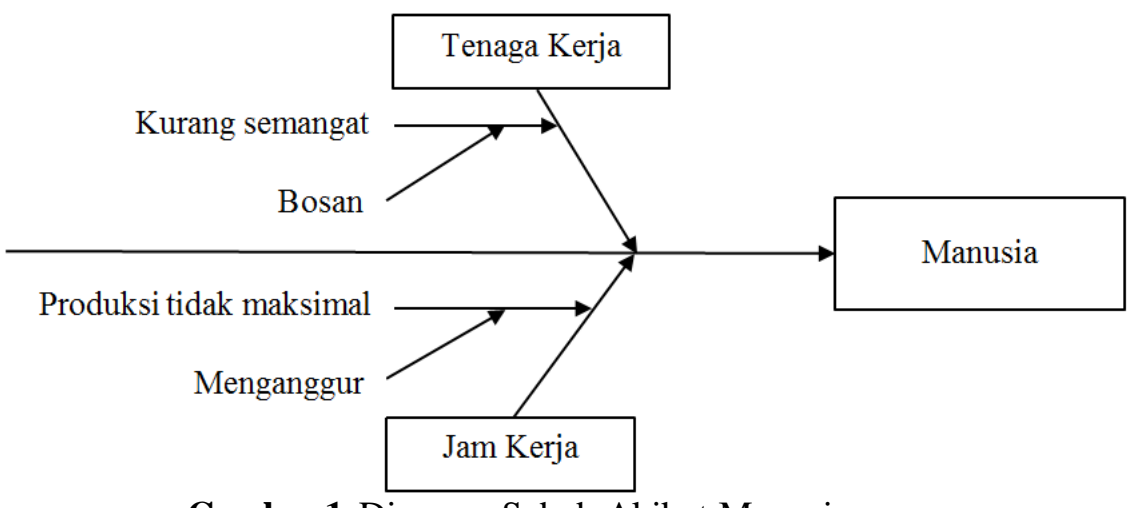

Gambar 1. Diagram Sebab Akibat Manusia

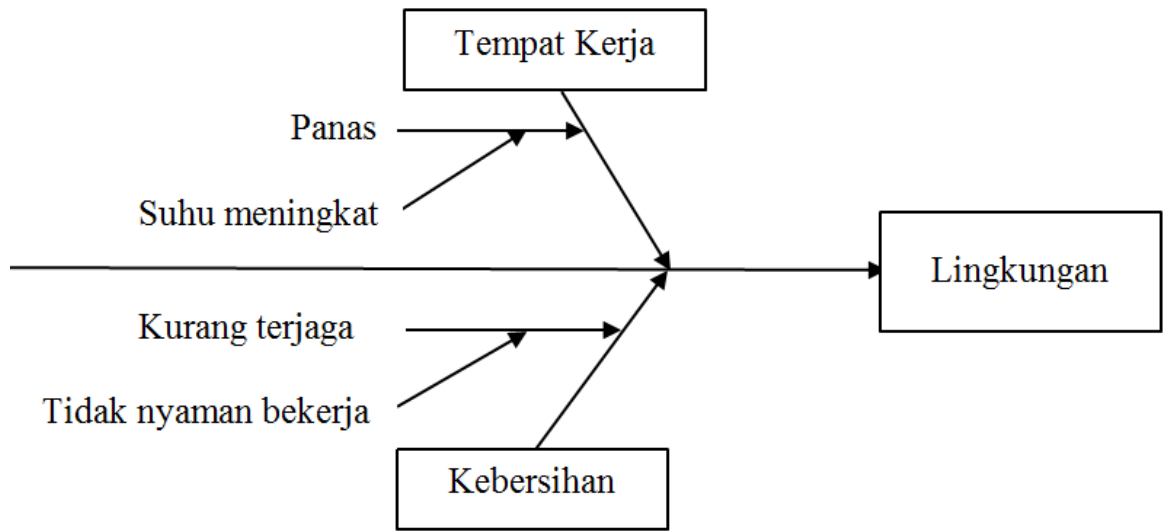

Gambar 2. Diagram Sebab Akibat Lingkungan

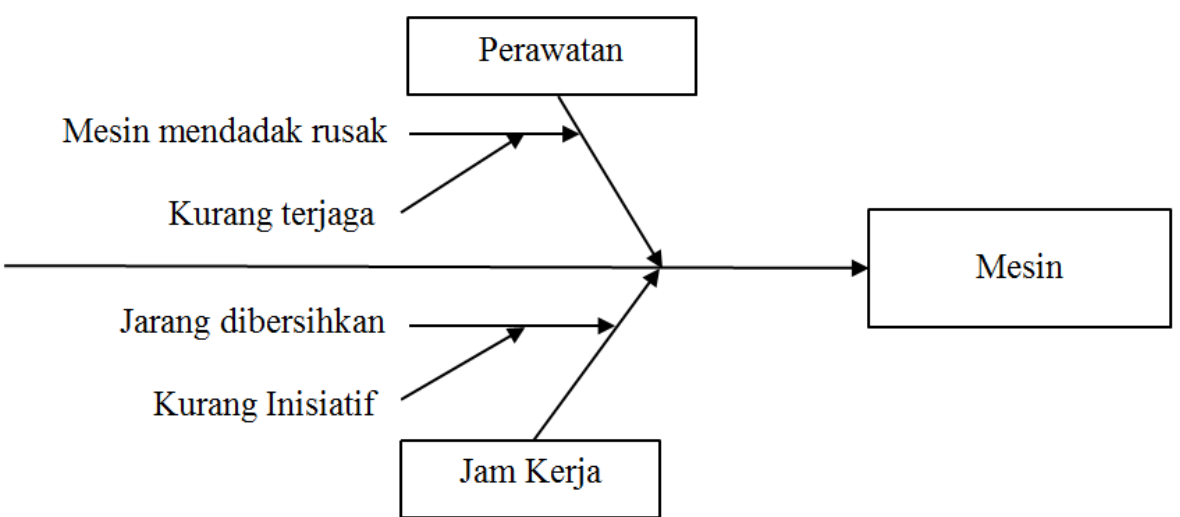

Gambar 3. Diagram Sebab Akibat Mesin 


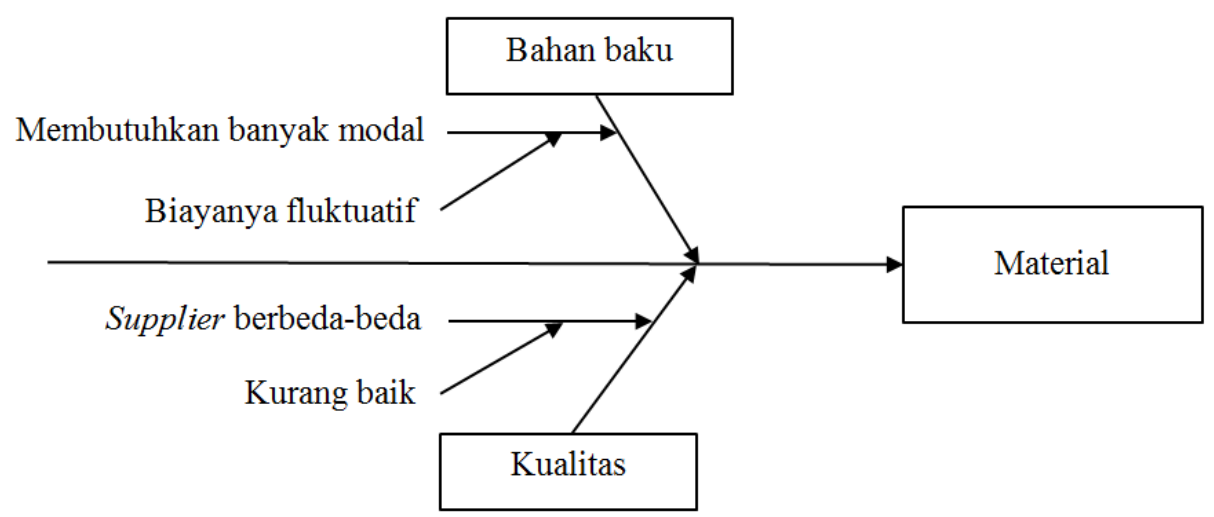

Gambar 4. Diagram Sebab Akibat Material

\section{Usulan Perbaikan dengan 5W+1H}

Setelah menganalisis penyebab penurunan produktivitas dengan diagram sebab akibat terhadap masing-masing faktor, maka selanjutnya dilakukan rencana usulan perbaikan dan diimplementasikan penerapannya dengan menggunakan tabel $5 \mathrm{~W}+1 \mathrm{H}$ guna memperbaiki tingkat produktivitas di UKM Roti Bernas. Adapun susunan tabel $5 \mathrm{~W}+1 \mathrm{H}$ untuk faktor penyebab dari setiap diagram sebab akibat dapat dilihat pada tabel 3, tabel 4, tabel 5, dan tabel 6 berikut.

Tabel 3. Usulan Perbaikan 5W+1H Faktor Manusia

\begin{tabular}{|c|c|c|c|c|c|c|}
\hline Penyebab & $\begin{array}{c}\text { What (Apa } \\
\text { Solusi) }\end{array}$ & $\begin{array}{c}\text { Why } \\
\text { (Mengapa } \\
\text { Diberi } \\
\text { Solusi) } \\
\end{array}$ & $\begin{array}{l}\text { When } \\
\text { (Kapan) }\end{array}$ & $\begin{array}{l}\text { Who } \\
\text { (Siapa) }\end{array}$ & $\begin{array}{l}\text { Where } \\
\text { (Dimana) }\end{array}$ & $\begin{array}{c}\text { How } \\
\text { (Tindakan } \\
\text { Yang } \\
\text { Dilakukan) }\end{array}$ \\
\hline $\begin{array}{l}\text { Tenaga } \\
\text { Kerja }\end{array}$ & $\begin{array}{l}\text { Mendengar } \\
\text { kan Musik }\end{array}$ & $\begin{array}{l}\text { Agar pekerja } \\
\text { tidak bosan } \\
\text { saat bekerja }\end{array}$ & $\begin{array}{l}\text { Setiap } \\
\text { kali } \\
\text { produksi } \\
\text { roti }\end{array}$ & $\begin{array}{c}\text { Pekerja } \\
\text { di UKM } \\
\text { Roti } \\
\text { Bernas }\end{array}$ & $\begin{array}{c}\text { Lantai } \\
\text { Produksi } \\
\text { UKM Roti } \\
\text { Bernas }\end{array}$ & $\begin{array}{c}\text { Memutarkan } \\
\text { lagu pop atau } \\
\text { dangdut }\end{array}$ \\
\hline Jam Kerja & $\begin{array}{c}\text { Mengontrol } \\
\text { Pekerja }\end{array}$ & $\begin{array}{l}\text { Agar pekerja } \\
\text { menjadi } \\
\text { lebih fokus }\end{array}$ & $\begin{array}{l}\text { Setiap } \\
\text { kali } \\
\text { produksi } \\
\text { roti }\end{array}$ & $\begin{array}{c}\text { Pekerja } \\
\text { di UKM } \\
\text { Roti } \\
\text { Bernas }\end{array}$ & $\begin{array}{c}\text { Lantai } \\
\text { Produksi } \\
\text { UKM Roti } \\
\text { Bernas }\end{array}$ & $\begin{array}{c}\text { Melakukan } \\
\text { pengawasan } \\
\text { terhadap } \\
\text { pekerja }\end{array}$ \\
\hline
\end{tabular}

Tabel 4. Usulan Perbaikan 5W+1H Faktor Lingkungan

\begin{tabular}{|c|c|c|c|c|c|c|}
\hline Penyebab & $\begin{array}{l}\text { What } \\
\text { (Apa } \\
\text { Solusi) }\end{array}$ & $\begin{array}{c}\text { Why } \\
\text { (Mengapa } \\
\text { Diberi } \\
\text { Solusi) } \\
\end{array}$ & $\begin{array}{l}\text { When } \\
\text { (Kapan) }\end{array}$ & $\begin{array}{l}\text { Who } \\
\text { (Siapa) }\end{array}$ & $\begin{array}{l}\text { Where } \\
\text { (Dimana) }\end{array}$ & $\begin{array}{c}\text { How } \\
\text { (Tindakan } \\
\text { Yang } \\
\text { Dilakukan) } \\
\end{array}$ \\
\hline $\begin{array}{l}\text { Tempat } \\
\text { Kerja }\end{array}$ & $\begin{array}{c}\text { Menambah } \\
\text { kan Kipas } \\
\text { Angin }\end{array}$ & $\begin{array}{l}\text { Agar suhu } \\
\text { ruang } \\
\text { produksi } \\
\text { menjadi } \\
\text { tidak panas }\end{array}$ & $\begin{array}{l}\text { Setiap } \\
\text { kali } \\
\text { produksi } \\
\text { roti }\end{array}$ & $\begin{array}{c}\text { Pekerja } \\
\text { di } \\
\text { UKM } \\
\text { Roti } \\
\text { Bernas }\end{array}$ & $\begin{array}{l}\text { Lantai } \\
\text { Produksi } \\
\text { UKM Roti } \\
\text { Bernas }\end{array}$ & $\begin{array}{c}\text { Membeli kipas } \\
\text { angin dan } \\
\text { langsung } \\
\text { digunakan }\end{array}$ \\
\hline Kebersihan & $\begin{array}{l}\text { Membersih } \\
\text { kan ruang } \\
\text { produksi } \\
\text { secara } \\
\text { rutin }\end{array}$ & $\begin{array}{l}\text { Agar ruang } \\
\text { produksi } \\
\text { menjadi } \\
\text { lebih bersih }\end{array}$ & $\begin{array}{l}\text { Setiap } \\
\text { kali } \\
\text { produksi } \\
\text { roti }\end{array}$ & $\begin{array}{c}\text { Pekerja } \\
\text { di } \\
\text { UKM } \\
\text { Roti } \\
\text { Bernas }\end{array}$ & $\begin{array}{l}\text { Lantai } \\
\text { Produksi } \\
\text { UKM Roti } \\
\text { Bernas }\end{array}$ & $\begin{array}{l}\text { Menyediakan } \\
\text { alat kebersihan } \\
\text { dan membuat } \\
\text { jadwal } \\
\text { pembersihan } \\
\text { tempat produksi }\end{array}$ \\
\hline
\end{tabular}

Tabel 5. Usulan Perbaikan 5W+1H Faktor Mesin

\begin{tabular}{lllllll}
\hline Penyebab & What & Why & When & Who & Where & How \\
\hline
\end{tabular}




\begin{tabular}{|c|c|c|c|c|c|c|}
\hline & $\begin{array}{c}\text { (Apa } \\
\text { Solusi) }\end{array}$ & $\begin{array}{c}\text { (Mengapa } \\
\text { Diberi Solusi) }\end{array}$ & (Kapan) & (Siapa) & (Dimana) & $\begin{array}{c}\text { (Tindakan } \\
\text { Yang } \\
\text { Dilakukan) }\end{array}$ \\
\hline Perawatan & $\begin{array}{l}\text { Membersih } \\
\text { kan mesin } \\
\text { produksi } \\
\text { secara } \\
\text { rutin }\end{array}$ & $\begin{array}{l}\text { Agar mesin } \\
\text { tidak } \\
\text { mengalami } \\
\text { masalah saat } \\
\text { melakukan } \\
\text { jalannya } \\
\text { produksi }\end{array}$ & $\begin{array}{l}\text { Setiap } \\
\text { kali } \\
\text { produksi } \\
\text { roti }\end{array}$ & $\begin{array}{c}\text { Pekerja } \\
\text { di } \\
\text { UKM } \\
\text { Roti } \\
\text { Bernas }\end{array}$ & $\begin{array}{l}\text { Lantai } \\
\text { Produksi } \\
\text { UKM Roti } \\
\text { Bernas }\end{array}$ & $\begin{array}{c}\text { Menyediakan } \\
\text { alat } \\
\text { kebersihan } \\
\text { dan membuat } \\
\text { jadwal } \\
\text { pembersihan } \\
\text { mesin } \\
\text { produksi }\end{array}$ \\
\hline Jam Kerja & $\begin{array}{l}\text { Melakukan } \\
\text { perawatan } \\
\text { secara } \\
\text { rutin }\end{array}$ & $\begin{array}{l}\text { Agar saat } \\
\text { proses } \\
\text { produksi roti } \\
\text { tidak mudah } \\
\text { terkontaminasi }\end{array}$ & $\begin{array}{l}\text { Setiap } \\
\text { kali } \\
\text { produksi } \\
\text { roti }\end{array}$ & $\begin{array}{c}\text { Pekerja } \\
\text { di } \\
\text { UKM } \\
\text { Roti } \\
\text { Bernas } \\
\end{array}$ & $\begin{array}{l}\text { Lantai } \\
\text { Produksi } \\
\text { UKM Roti } \\
\text { Bernas }\end{array}$ & $\begin{array}{c}\text { Membuat } \\
\text { jadwal } \\
\text { maintenance } \\
\text { secara kontinu }\end{array}$ \\
\hline
\end{tabular}

Tabel 6. Usulan Perbaikan 5W+1H Faktor Material

\begin{tabular}{|c|c|c|c|c|c|c|}
\hline Penyebab & $\begin{array}{c}\text { What (Apa } \\
\text { Solusi) }\end{array}$ & $\begin{array}{c}\text { Why } \\
\text { (Mengapa } \\
\text { Diberi } \\
\text { Solusi) }\end{array}$ & $\begin{array}{c}\text { When } \\
\text { (Kapan) }\end{array}$ & $\begin{array}{c}\text { Who } \\
\text { (Siapa) }\end{array}$ & $\begin{array}{c}\text { Where } \\
\text { (Dimana) }\end{array}$ & $\begin{array}{c}\text { How } \\
\text { (Tindakan } \\
\text { Yang } \\
\text { Dilakukan) }\end{array}$ \\
\hline $\begin{array}{c}\text { Bahan } \\
\text { Baku }\end{array}$ & $\begin{array}{c}\text { Merencanakan } \\
\text { pemesanan } \\
\text { bahan baku }\end{array}$ & $\begin{array}{c}\text { Agar tidak } \\
\text { perlu } \\
\text { mengeluar } \\
\text { kan banyak } \\
\text { modal }\end{array}$ & $\begin{array}{l}\text { Setiap kali } \\
\text { produksi } \\
\text { roti }\end{array}$ & $\begin{array}{c}\text { Pekerja } \\
\text { di } \\
\text { UKM } \\
\text { Roti } \\
\text { Bernas }\end{array}$ & $\begin{array}{l}\text { Lantai } \\
\text { Produksi } \\
\text { UKM Roti } \\
\text { Bernas }\end{array}$ & $\begin{array}{c}\text { Melakukan } \\
\text { perhitungan } \\
\text { mengenai } \\
\text { stok bahan } \\
\text { secara rutin }\end{array}$ \\
\hline Kualitas & $\begin{array}{l}\text { Menentukan } \\
\text { satu supplier } \\
\text { tetap }\end{array}$ & $\begin{array}{c}\text { Agar } \\
\text { kualitas } \\
\text { bahan baku } \\
\text { meningkat } \\
\text { namun } \\
\text { harga tidak } \\
\text { meningkat }\end{array}$ & $\begin{array}{l}\text { Setiap kali } \\
\text { produksi } \\
\text { roti }\end{array}$ & $\begin{array}{c}\text { Pekerja } \\
\text { di } \\
\text { UKM } \\
\text { Roti } \\
\text { Bernas }\end{array}$ & $\begin{array}{l}\text { Lantai } \\
\text { Produksi } \\
\text { UKM Roti } \\
\text { Bernas }\end{array}$ & $\begin{array}{c}\text { Menjalin } \\
\text { hubungan } \\
\text { yang baik } \\
\text { dengan } \\
\text { distributor } \\
\text { bahan baku }\end{array}$ \\
\hline
\end{tabular}

\section{Data Input dan Output (Setelah Implementasi)}

Setelah implementasi perbaikan, maka dilakukan perhitungan produktivitas kembali dengan mengumpulkan data input dan output selama 3 periode waktu yaitu bulan Maret 2021 sebagai periode dasar dan bulan April dan Mei 2021 sebagai periode yang diukur. Berikut ini adalah data input dan output dari UKM Roti Bernas yang telah direkap jumlahnya dan ditotalkan hasil dari pengumpulan data sebelumnya sebagai berikut pada tabel 7 .

Tabel 7. Data Input dan Output UKM Roti Bernas Setelah Implementasi

\begin{tabular}{|c|c|c|c|c|}
\hline No & Keterangan & $\begin{array}{c}\text { Maret } 2021 \\
\text { (Periode dasar) }\end{array}$ & April 2021 & Mei 2021 \\
\hline \multicolumn{5}{|c|}{ Output } \\
\hline 1 & Roti Tawar & $\operatorname{Rp} 36.744 .000$ & Rp 40.128.000 & Rp 34.200.000 \\
\hline 2 & Roti Tawar Kupas & $\mathrm{Rp} 31.780 .000$ & Rp 33.360 .000 & $\operatorname{Rp} 29.430 .000$ \\
\hline 3 & Roti Manis & $\mathrm{Rp} 43.850 .000$ & $\mathrm{Rp} 41.570 .000$ & Rp 33.340.000 \\
\hline & Total Output & Rp 112.374.000 & Rp 115.058.000 & Rp 96.970.000 \\
\hline \multicolumn{5}{|c|}{ Input } \\
\hline 1 & Depresiasi & Rp 448.192 & Rp 444.800 & Rp 364.624 \\
\hline
\end{tabular}




\begin{tabular}{llccc}
2 & Tenaga Kerja & $\mathrm{Rp} 9.100 .000$ & $\mathrm{Rp} 8.750 .000$ & $\mathrm{Rp} 7.700 .000$ \\
3 & Material & $\mathrm{Rp} 36.328 .000$ & $\mathrm{Rp} \mathrm{32.727.000}$ & $\mathrm{Rp} \mathrm{28.054.000}$ \\
4 & Energi Listrik & $\mathrm{Rp} 183.500$ & $\mathrm{Rp} 167.700$ & $\mathrm{Rp} 142.400$ \\
5 & Maintenance & $\mathrm{Rp} 255.000$ & $\mathrm{Rp} 242.000$ & $\mathrm{Rp} \mathrm{217.000}$ \\
\hline & Total Input & $\mathrm{Rp} \mathrm{46.314.692}$ & $\mathrm{Rp} \mathrm{42.331.500}$ & $\mathrm{Rp} \mathrm{36.478.024}$ \\
\hline
\end{tabular}

\section{Hasil Indeks Produktivitas Parsial dan Total (Setelah Implementasi)}

Berikut ini pada tabel 8 yang menunjukkan hasil indeks produktivitas parsial dan total setelah implementasi pada UKM Roti Bernas terhadap masingmasing jenis input.

Tabel 8. Hasil Indeks Produktivitas UKM Roti Bernas Setelah Implementasi

\begin{tabular}{clccc}
\hline No & Jenis Input & $\begin{array}{c}\text { Maret 2021 } \\
\text { (Periode } \\
\text { dasar) }\end{array}$ & $\begin{array}{c}\text { April 2021 } \\
\text { (Periode yang } \\
\text { diukur) }\end{array}$ & $\begin{array}{c}\text { Mei 2021 } \\
\text { (Periode yang } \\
\text { diukur) }\end{array}$ \\
\hline 1 & Depresiasi & 100 & 103,17 & 106,07 \\
2 & Tenaga Kerja & 100 & 106,48 & 107,36 \\
3 & Material & 100 & 113,45 & 111,74 \\
4 & Energi Listrik & 100 & 112,04 & 110,20 \\
5 & Maintenance & 100 & 107,89 & 102,43 \\
6 & Indeks Total & 100 & 112,06 & 109,55 \\
\hline
\end{tabular}

\section{Kesimpulan}

Hasil indeks produktivitas terhadap masing-masing input (depresiasi, tenaga kerja, material, energi listrik, dan maintenance) pada tahun 2020 adalah $81,03 \% ; 84,72 \% ; 88,06 \%$; $102,48 \%$; $75,32 \%$; dan indeks total $87,35 \%$. Indeks total adalah perbandingan nilai total nilai indeks produktivitas output dengan total nilai indeks produktivitas input suatu periode dengan indeks produktivitas periode sebelumnya (Anggraini, 2013). Faktorfaktor yang mempengaruhi penurunan produktivitas tersebut yaitu manusia, lingkungan, mesin, dan material dengan menganalisis faktor penyebab menggunakan diagram sebab akibat. Faktor penyebab dari manusia yaitu para pekerja merasa bosan dan menganggur saat jam kerja. Faktor penyebab dari lingkungan yaitu tempat produksi panas dan kebersihan tempat produksi kurang terjaga. Faktor penyebab dari mesin yaitu perawatan mesin terbatas dan mesin mendadak rusak. Dan faktor penyebab dari material yaitu harga bahan baku fluktuatif dan kualitas bahan baku yang kurang baik. Setelah menganalisis penyebab penurunan produktivitas dengan diagram sebab akibat, maka dibuat usulan perbaikan dengan menggunakan tabel $5 \mathrm{~W}+1 \mathrm{H}$ yang diimplementasikan dengan tujuan peningkatan produktivitas berdasarkan faktor penyebab dari hasil diagram sebab sebelumnya. Dengan adanya pelaksanaan implementasi, maka indeks produktivitas setelah implementasi terhadap masingmasing input (depresiasi, tenaga kerja, material, energi listrik, dan maintenance) pada bulan April 2021 berturut-turut adalah $103,17 \%$; 106,48 \%; 113,45\%; $112,04 \% ; 107,89 \%$ dan indeks total $112,06 \%$. Sedangkan indeks produktivitas pada bulan Mei 2021 berturut-turut adalah 106,07 \%; 107,36 $\% ; 111,74 \% ; 110,20 \% ; 102,43 \%$; dan indeks total $109,55 \%$. Pengukuran produktivitas yang telah dilakukan berjalan dengan baik dengan penerapan implementasi perbaikan yang efektif \& efisien serta penggunaan input yang lebih ekonomis. 
Daftar Pustaka

Anggraini, Iunike Galah, 2013, Pengukuran dan Faktor-Faktor yang Mempengaruhi Produktivitas pada Bagian Produksi Wooden Carpet Studi Kasus: CV Natural Palembang, Skripsi, Sekolah Tinggi Teknik Musi.

Ariani, Dorotea Wahyu, (2004), Pengendalian Kualitas Statistik, Yogyakarta.

Gaspersz, Vincent, (2005) Total Quality Management, Jakarta: PT. Gramedia Pustaka Utama.

Heizer, Jay dan Barry Render, (2016), Manajemen Operasi, Edisi Sebelas, Jakarta: Salemba Empat.

Masharyono, (2016), Pengaruh Kualitas Produk Terhadap Kepuasan Konsumen Pada Celdi Katering (Survei Pada Konsumen Celdi Katering), Jurnal Universitas Pendidikan Indonesia Bandung, Vol. 01, No. 02.

Sinaga, Daniel, 2015, Analisis Produktivitas dengan Metode Marvin E. Mundel pada PT. Karya Murni Perkasa, Skripsi, Universitas Sumatera Utara.

Sinungan, Muchdarsyah, (2015), Produktivitas : Apa dan Bagaimana, Edisi Kesembilan, Jakarta: Bumi Aksara.

Sumanth, David J, (1990), Productivity Engineering and Management, New York: Mc Graw - Hill Book Company. 